\title{
TECCIENCIA
}

\section{Grafting telinne monspessulana fiber with vinyl-trimethoxysilane. Effect of dicumyl peroxide catalyst}

\author{
Injerto de fibra monspesullana telinne con vinil-trimetoxisilano \\ Efecto de catalizado de peróxido de dicumilo
}

\author{
Arnoldo Emilio Delgado Tobón ${ }^{1}$, Oscar Yecid Buitrago Suescún², \\ William Arnulfo Aperador Chaparro ${ }^{3}$ \\ ${ }^{1}$ Universidad Militar Nueva Granada, Bogotá, Colombia, Arnoldo.delgado@unimilitar.edu.co \\ ${ }^{2}$ Universidad Militar Nueva Granada, Bogotá, Colombia, oscar.buitrago@unimilitar.edu.co \\ ${ }^{3}$ Universidad Militar Nueva Granada, Bogotá, Colombia, William.aperador@unimilitar.edu.co
}

\begin{abstract}
The use of natural fibers as reinforcing fillers involves performing surface treatments to reduce hydrophilicity and improve the compatibility of the vegetable particle with polymers. In this investigation natural Smooth Retama fiber (Telinne Monspessulana) was treated with silane coupling agent vinyl-trimethoxysilane (VTMS). Silane was pre-hydrolyzed in aqueous ethanol /water $80 / 20$ for $1 \mathrm{~h}$, maintaining the $\mathrm{pH}$ between 3.0-3.5. Subsequently, the fiber was immersed in the solution of pre-hydrolyzed silane for $3 \mathrm{~h}$. Treated fiber was washed with distilled water and dried for $24 \mathrm{~h}$ at $45^{\circ} \mathrm{C}$. Finally, soxhlet extraction was performed to the fiber to remove residual silane. The influence of dicumyl peroxide (DCP) catalyst on the silane grafting process with the natural fiber was analyzed. By analyzing infrared spectroscopy FTIR, ash content, and scanning electron microscopy (SEM) quantitatively and qualitatively the positive effect of organic peroxide was determined as a catalyst for VTMS.
\end{abstract}

Keywords: Coupling, grafting, DCP, SCA, Telinne Monspessulana, VTMS

\section{Resumen}

El uso de fibras naturales como cargas de refuerzo implica la necesidad de realizar tratamientos superficiales para reducir el carácter hidrófilo y mejorar la compatibilidad de la partícula vegetal con polímeros. En esta investigación, fibra natural de Retamo Liso (Telinne Monspessulana) fue tratada con agente de acoplamiento vinil-trimetoxisilano (VTMS). El silano fue pre-hidrolizado en solución acuosa de etanol/agua 80/20 durante una hora manteniendo el pH entre 3,0 y 3,5. Posteriormente, la fibra fue sumergida en la solución de silano pre-hidrolizado durante $3 \mathrm{~h}$. Después, la fibra se lavó con agua destilada y fue secada durante $24 \mathrm{~h} \mathrm{a} 45^{\circ} \mathrm{C}$. Finalmente, se realizó extracción soxhlet a la fibra para eliminar el silano residual. Se analizó la influencia del catalizador peróxido de dicumilo (DCP) sobre el proceso de injerto del silano con la fibra natural. Por medio del análisis de espectroscopía de infrarrojo FTIR, contenido de cenizas y microscopia de barrido electrónico (SEM) se logró determinar de forma cuantitativa y cualitativa el efecto positivo del peróxido orgánico como catalizador del VTMS.

Palabras clave: Acoplamiento, DCP, injerto, silano, Telinne Monspessulana, VTMS

*Corresponding Author.

E-mail: Arnoldo.delgado@unimilitar.edu.co

Tel: $57+1+6343200$ Ext: 1274
How to cite: Delgado, A.; Buitrago, O.; Aperador, W., Grafting telinne monspessulana fiber with vinyl-trimethoxysilane. Effect of dicumyl peroxide catalyst , TECCIENCIA, Vol. 7 No. 18., 20-24, 2015, DOI: http:/dx.doi.org/10.18180/tecciencia.2015.18.4 


\section{TECCIENCIA}

\section{Introduction}

The importance of natural fibers as possible substitutes for mineral fillers in the manufacture of polymer compounds has been broadly researched. Among the advantages of plant fibers, we can highlight their sustainable production, nontoxicity and low density. In spite of the promising panorama, the use of fibers as true reinforcing fillers implies the need for surface treatments to diminish hydrophilic nature, which generates incompatibility between the plant particle and the polymer matrix [1] [2] [3].

Several strategies exist to diminish the hydrophilic nature, among these are the mercerizing, acetylation, benzoylation and coupling surface treatments of the fiber through silane coupling agents (SCA). The advantage of treating the natural fiber with silanes lies in that the particle loses its hydrophilic nature due to the formation of a bond between part of the silane with the hydroxyl groups present in the cellulose, one of the main components of the natural fibers [4] [5] [6] [7]. The SCA are organic molecules that have the following chemical structure: $R_{(4-n)}-S i-\left(R^{\prime}-X\right)_{n}$ with $\mathrm{n}=1.2 . R$ is an alkyl group bonded to an oxygen atom, $R$ ' is an alkyl bond that binds the silicon to the functional group $X$. Silanes are classified according to the functional group, the following groups are highlighted: vinyl, amino, and methacryl [4].

The mechanism to treat the fiber with the silane to achieve adequate coupling comprises four stages. Initially, the SCA must be pre-hydrolyzed in the presence of an alcohol aqueous solution or another solvent like acetone; the objective is the formation of small units called silanols that contain highly reactive $-\mathrm{OH}$ groups.

Generally, the dissolution takes place at room temperature and the times can vary according to the type of silane and solvent. During the following stage, denominated selfcondensation, the molecular weight of the silanols is controlled through continuous adjustment of $\mathrm{pH}$ by adding sulfuric or acetic acid, generally the $\mathrm{pH}$ recommended is between 3 and 4.5. Strict control is required of the process, for example, prolonged times may lead to the formation of oligomers of high molecular weight, and hindering their absorption on the particle surface. During the third stage physical adsorption occurs of the reactive silanols through the hydroxyl groups of fiber via the formation of hydrogen bonds. The final stage consists of the actual formation of the silanol graft with the natural fiber, once the solvent had been eliminated and with increased temperature the formation of the $-\mathrm{Si}-\mathrm{O}-\mathrm{C}$ - bond takes place with release of water [4] [8].

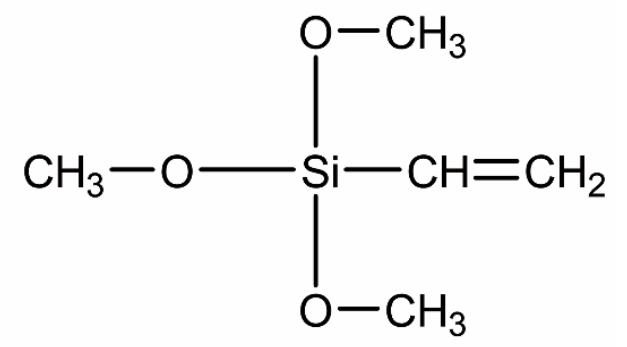

Figure 1 Structure of the VTMS coupling agent

This research analyzed the coupling of the Telinne Monspessulana (TMF) natural fiber to vinyltrimethoxysilane VTMS (Figure 1). The TM shrub is an invasive species from the Colombian Andean zone. The VTMS silane has specific industrial application in coupling silicon-type mineral fillers to rubber (using peroxide crosslinking). However, this coupling agent has been the object of extensive research where it has been used to modify the surface of natural fibers. Some authors have proposed that its effectiveness increases with the incorporation of organic peroxide-type catalysts [4] [5] The fundamental aim of the research was to analyze the effect of incorporating dicumyl peroxide (DCP) ask catalyst for VTMS during the coupling process with the TMF natural fiber.

\section{Materials and Methods}

\subsection{Materials}

The materials used in the investigation were: TMF with particle diameter of $500 \mu \mathrm{m}, 0.21 \%$ humidity. A VTMS coupling agent: Struktol ${ }^{\circledR}$ 972- purity $>98.6 \%$ elaborated by Struktol ${ }^{\circledR}$. The DCP catalyst: Perkadox ${ }^{\circledR}$ BC FF, 99\% purity, manufactured by Akzo Nobel ${ }^{\circledR}$. The solvents used were: ethyl alcohol at $96 \%$ produced by Sucroal $^{\circledR}$ S.A and deionized water in a conductivity interval between 3.0 and $6.5 \mu \mathrm{S} / \mathrm{cm}$. The $\mathrm{pH}$ adjustment was carried out with glacial acetic acid at $99.6 \%$ purity.

\subsection{Procedure}

This study evaluated the effect of the DCP catalyst with the VTMS coupling agent; the silane concentration was $10 \%$ ( $\mathrm{p} / \mathrm{p}$ with respect to the fiber). The fiber-silane coupling included the following stages:

\subsubsection{Pre-hydrolysis of silane}

Two types of pre-hydrolysis were carried out:

A: $1.25 \mathrm{~g}$ of VTMS were added to $250 \mathrm{~mL}$ of ethanol aqueous solution at $80 \%$.

B: $1.25 \mathrm{~g}$ of VTMS plus $0.125 \mathrm{~g}$ of DCP were added to 250 $\mathrm{mL}$ of ethanol aqueous solution at $80 \%$. 


\section{TECCIENCIA}

Each of the solutions were kept under constant agitation at $25^{\circ} \mathrm{C}$ during $1 \mathrm{~h}$ and the $\mathrm{pH}$ was adjusted between 3.0 and 3.5 by adding glacial acetic acid. During this stage the silanols are formed.

\subsubsection{Fiber immersion}

A total of $12.5 \mathrm{~g}$ of TMF were submerged in each of the prehydrolyzed silane solutions. Constant agitation was kept constant during $4 \mathrm{~h}$ at $25^{\circ} \mathrm{C}$. During this stage the fiber surface absorbs the silanols (Figure 2).

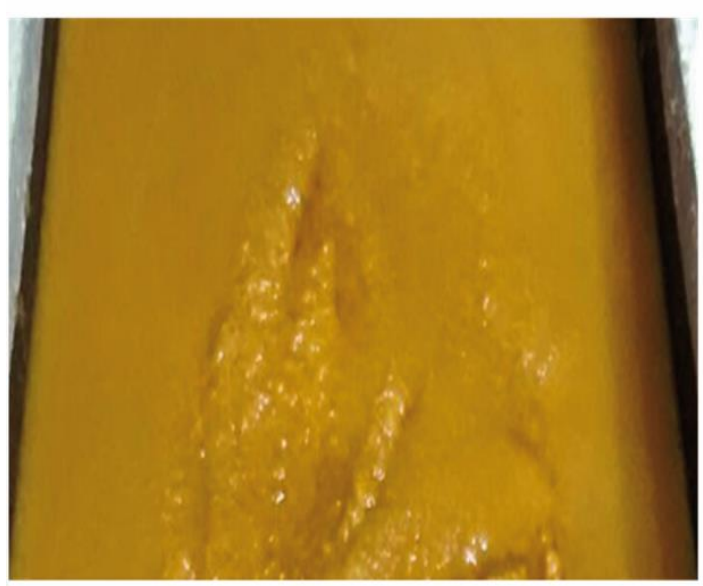

TMF immersion in prehydrolyzed VTMS/DCP solution

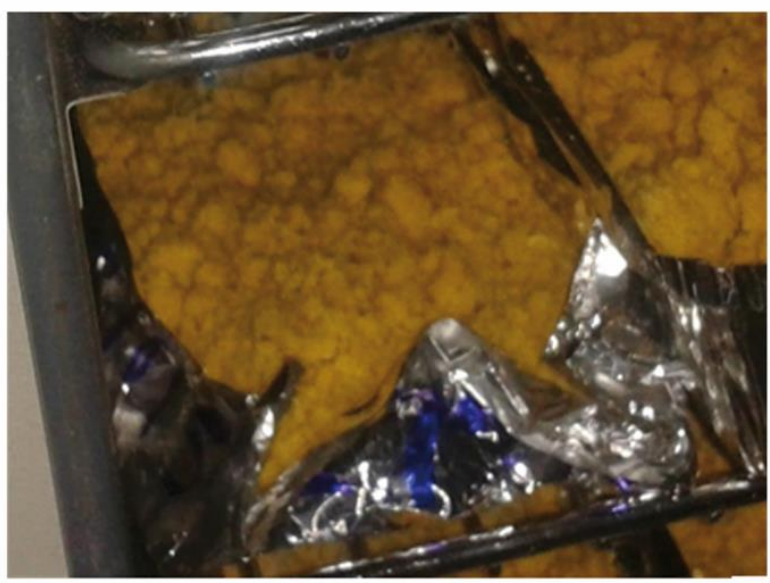

TMF-VTMS/DCP Graft

process

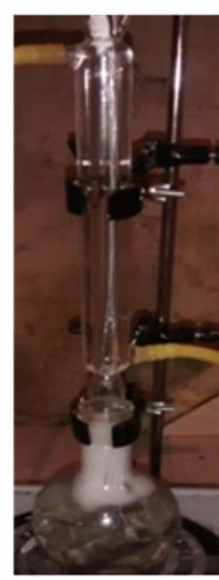

Soxhlet wash grafted TMF

Figure 2 Scheme of the TTMF fiber coupling process

\subsubsection{Washing of the fiber}

After the immersion stage, each of the fibers were washed with deionized water to eliminate the solvent, acetic acid, and silane.

\subsubsection{VTMS-TL fiber silane graft}

To guarantee the VTMS graft on the fiber, both fibers were heated to $45^{\circ} \mathrm{C}$ during $24 \mathrm{~h}$. This process was carried out in a forced-convection oven (Figure 2).

\subsubsection{Soxhlet extraction}

This was carried out with acetone to eliminate residual silanols; each of the fibers was subjected to soxhlet extraction during $8 \mathrm{~h}$ at $54{ }^{\circ} \mathrm{C}$. The extraction equipment is

integrated by a heating mantle, a 500-ml balloon and a condenser (Figure 2).

\subsection{Analysis methods}

\subsubsection{FTIR spectroscopy}

NICOLET iS $10^{\circledR}$ equipment was used. The pulverized fiber $(1 \mathrm{mg})$ was mixed with $80 \mathrm{mg}$ of potassium bromide $(\mathrm{KBr})$; by pressing, $\mathrm{KBr}$ windows were obtained. The wavelength interval chosen was between 4000 and $400 \mathrm{~cm}^{-1}$.

\subsubsection{Scanning Electron Microscopy (SEM)}

The fiber morphology was observed under microscope (FEI QUANTA $^{\circledR} 200$ ) under low-vacuum conditions, 30-kV acceleration. The surface metallization treatment of the fibers was carried out with a Balzers ${ }^{\circledR}$ metalizing equipment (SDC 050) achieving a pale-gold film with approximate thickness of $\pm 5 \mathrm{~nm}$.

\subsubsection{Ash content}

Through the ashes, the grafted silane content was determined. Initially, approximately $0.5 \mathrm{~g}$ of fiber was weighed in a crucible and introduced into an electric oven (COFI) with pyrometer (PowerLine XTM) at $600{ }^{\circ} \mathrm{C}$ for 8 $\mathrm{h}$. Six repetitions were performed to obtain the average.

\section{Results}

Prior to the FTIR, ash, and SEM analyses, the fibers that came into contact with the silane were subjected to soxhlet extraction to eliminate the residual silane and guarantee correct analysis. Upon analyzing the FTIR extraction bands, from Figure 3 bands/peaks are observed in the 1740 and $1250 \mathrm{~cm}^{-1}$ wavelengths, related to stretching of the carbonyl and acetyl groups, respectively, of the hemicellulose. 


\section{TECCIENCIA}

Additionally, the $3420,1510,1460$, and $1160 \mathrm{~cm}^{-1}$ wavelengths are observed, related to the vibrational stretching of the $-\mathrm{OH},-\mathrm{C}-\mathrm{C}-$ groups, the $-\mathrm{CH}_{3}$ and-C-O-C methyl group of the cellulose, respectively. Finally, the 2925 and $2850 \mathrm{~cm}^{-1}$ bands are observed, corresponding to the stretching of the methyl $-\mathrm{CH}_{3}$ and methylene $-\mathrm{CH}_{2}$ groups, distributively. It was not possible to determine, via FTIR analysis, the Si-O-C bond, corresponding to the silicon coupling with the fiber, which probably overlap in the 950$1150 \mathrm{~cm}^{-1}$ wave interval.

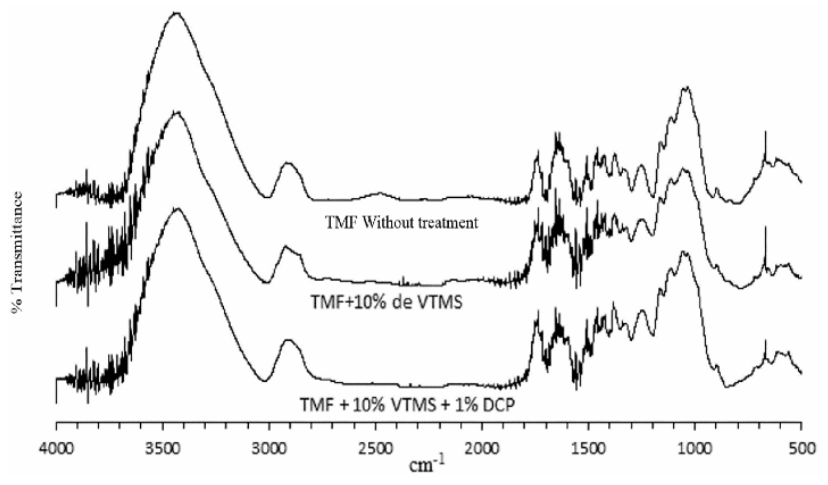

Figure 3 FT IR of TMF subjected to coupling with VTMS/DCP

Given that it was not possible to determine the coupling of the RL fiber with the VTMS via FTIR analysis, a test was made to convert each of the fibers into ash. If the fiber has VTMS grafted, it means the silicon will also be bound to the chemical bond (silicon is part of the silanols). Upon subjecting the fiber to calcination, the silicon will become silicon oxide.

Through this methodology it was possible to note differences in ashes via infrared analysis (Figure 4). Clearly, the spectrum corresponding to the ash grafted with VTMS/DCP presents peaks in the wavelength interval comprised between 950 and $1250 \mathrm{~cm}^{-1}$, which correspond to the silicon oxide vibrational stretching, as well as to different polymorphic forms of silica [9], [10]. It is also noted that the ash spectra corresponding to the fiber without treatment and to the fiber treated only with VTMS do not present big differences. The importance of adding DCP is wellmanifested to accomplish effective coupling of the silane with the natural fiber. Other peaks are highlighted, for example at $3450 \mathrm{~cm}^{-1}$, attributed to stretching of the $-\mathrm{OH}$ group produced when the ash absorbs humidity during manipulation, the peak at $1480 \mathrm{~cm}^{-1}$ due to the presence of magnesium carbonate, peaks 1420 and $880 \mathrm{~cm}^{-1}$ are due to symmetric and asymmetric stretching of calcium carbonate [9] [10] [11].

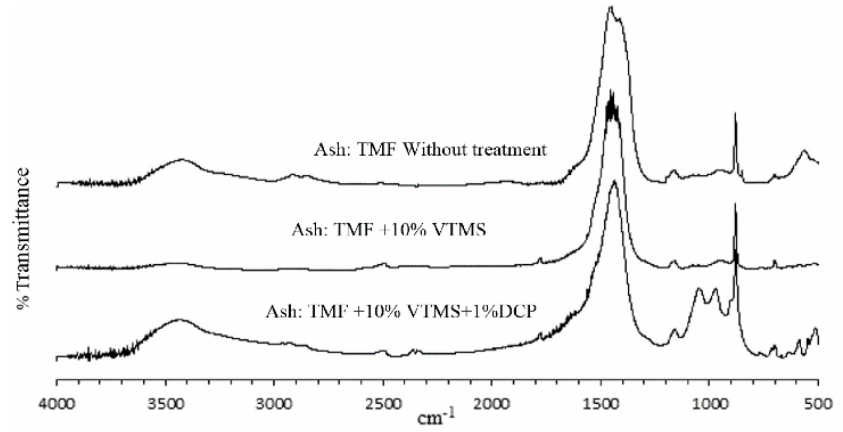

Figure 4 FTIR analysis of ash from fibers subjected to coupling with VTMS/DCP

With respect to the effectiveness of using DCP as catalyst in the VTMS coupling reaction, two additional tests permit confirming the influence of the organic peroxide. The ash content analysis (Figure 5) yields the highest value of ashes for the fiber grafted with VTMS/DCP, confirming that the increase of ashes corresponds to the formation of silicon oxide. The value of ashes of the fiber coupled with VTMS/DCP was $8.6 \%$ vs. 0.6 and $0.4 \%$ of the fiber treated with VTMS and without treatment, respectively.

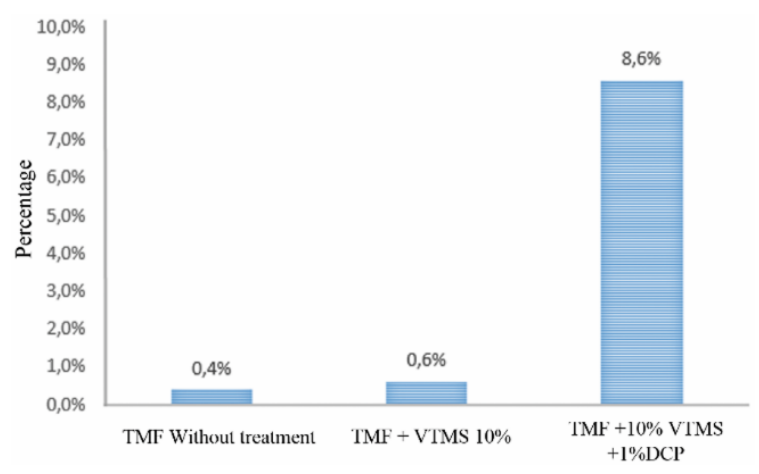

Figure 5 Ash percentage of TMF subjected to coupling with VTMS/DCP

Finally, morphological analysis was conducted of the fiber coupled with VTMS/DCP and the fiber treated only with VTMS. Figure 6 shows differences on the surfaces of the fibers. The TMF particle grafted with VTMS/DCP presents a different morphology from the TMF particle treated only with VTMS; the formation of small filaments can be seen on the particle surface, which do not exist on the particle treated with silane without addition of DCP. The small filaments may be associated to the formation of grafts on the fiber surface. Once again, the effectiveness of DCP is proven as catalyst of the VTMS silane in grafting or coupling processes of Smooth Retama fiber. 


\section{TECCIENCIA}

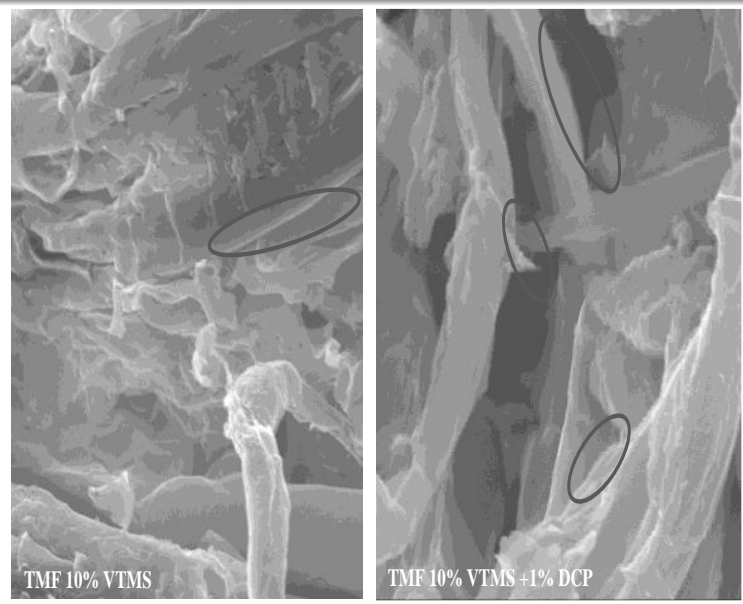

Figure 6 SEM 2000x. TMF coupled to VTMS/DCP

\section{Conclusions}

Through three analysis methods, FTIR, ash percentage, and SEM, we managed to test the importance of adding DPC organic peroxide as catalyst of the VTMS silane, which has vinyl as functional group. It is clear that VTMS is not hydrolyzed and, hence, does not act as a coupling agent in the Telinne Monspessulana natural fiber without the presence of the organic peroxide.

Further studies will be necessary to establish the optimal VTMS/DCP ratio. It is also interesting to analyze the possible variation of parameters like hydrolysis time, alcohol/water ratio, and the graft process conditions.

\section{Acknowledgments}

This article was derived from the project (INV-ING-1341), funded by the Vice-rectory of Research at Universidad Militar Nueva Granada - Validation 2014.

\section{References}

[1] A. C. Miller y J. C. Berg, «Effect of silane coupling agent adsorbate structure on adhesion performance with a polymeric matrix, Composites Part A: Applied Science and Manufacturing, vol. $34, \mathrm{n}^{\circ}$ 4, pp. 327-332, 2003.

[2] L. Xue, G. T. Lope y P. Satyanarayan, «Chemical Treatments of Natural Fiber for Use in Natural Fiber-Reinforced Composites: A Review» Journal Polymers Enviromental, vol. 15, n 1, pp. 25-33, 2007.

[3] C. Castro, A. Palencia, I. Gutiérrez, G. Vargas y P. Gañán, «Determination of optimal alkaline treatment conditions for fique fiber bundles as reinforcement of composites materials,» Revista Técnica Ingeniería Universidad de Zulia, vol. 30, n² 2, pp. 136-142, 2007.

[4] Y. Xie, A. Z. X. H. Callum, H. Militz y C. Mai, «Silane coupling agents used for natural fiber/polymer composites: A review,» Composites: Part A, vol. 41, no 1, pp. 806-819, 2010.

[5] L. Fang, L. Chang, W.-J. Guo, Y. Chen y Z. Wang, «Influence of silane suface modification on veneer on interfacial adhesion of wood-plastic plywood,» Applied surface sicence, vol. 288, $\mathrm{n}^{\circ}$ 1, pp. 682-689, 2014

[6] O. Asumani, R. Reid y R. Paskaramoorthy, « The effects of alkalisilane treatment on the tensile and flexural properties of short fibre non-woven kenaf reinforced polypropylene composites, , Composites: Part A, vol. 43, $\mathrm{n}^{\circ}$ 1, pp. 1431-1440, 2012.

[7] G. Grubbstrom y K. Oksman, «Influence of wood flour moisture content on the degree of silane- crosslinking and its relationship to structure- property relations of wood thermoplastic composites,» Composites science and technology, vol. 69, $\mathrm{n}^{\circ}$ 7-8, pp. 1045-1050, 2009.

[8] K. S. Chun, S. Husseinsyah y H. Osman, «Mechanical and Thermal Properties of Coconut Shell Powder Filled Polylactic Acid Biocomposites: Effects of the Filler Content and Silane Coupling Agent,» Journal of Polymer Research, vol. 19, nº 5, pp. 1-8, 2012.

[9] D. Cho, H. Lee y S. Han, «Effect of fiber surface modification on the interfacial and mechanical properties of kenaf fiber-reinforced thermoplastic and thermosetting polymer composites,» Composite Interfaces, vol. 16, $\mathrm{n}^{\circ}$ 7, pp. 11-29, 2009.

[10] M. Bengtsson, P. Gatenholm y K. Oksman, «The effect of crosslinking on the properties of polyethylene/wood flour composites,» Composites Science and Technology Journal Impact Factor \& Information, vol. 65, n 10, pp. 1468-1479, 2005.

[11] D. Govindarajan y G. Jayalakshmi, «XRD, FTIR and Microstructure Studies of Calcined Sugarcane Bagasse Ash,, Advances in Applied Science Research, vol. 2, n 3, pp. 544-549, 2011. 